\title{
Soberanía y castigo en Charcas. La represión militar y judicial de las juntas de La Plata y La Paz, 1808-1810
}

\author{
Marta IRUROZQUI Victoriano \\ GEA, IH-CSIC \\ marta.irurozqui@cchs.csic.es
}

Recepción: 2 de marzo de 2011 / Revisión: 23 de mayo de 2011

Aceptación: 15 de marzo de 2011 / Publicación: diciembre de 2011

\section{RESUMEN}

Tanto la represión militar de las juntas de La Plata y La Paz en 1810, como su refrendo judicial con condenas de naturaleza diversa, hacían referencia a la resolución de un doble conflicto intracontinental de autoridad y de influencias jurisdiccionales: entre los virreyes e intendentes frente a otros cuerpos como la audiencia; y entre los virreinatos del Río de La Plata y del Perú. De la conversión de Charcas a través de la violencia en un seguro de supervivencia y conservación de los espacios y potestades virreinales resultó la pérdida de la posibilidad de que una institución delegativa real -la audiencia- asumiera legítimamente la soberanía indivisa, favoreciéndose con ello la dispersión de la misma a través de los cabildos.

Palabras clave: Violencia, soberanía, red de juntas, represión militar, proceso judicial, Charcas, audiencia, cabildos, virreinato del Río de La Plata, virreinato del Perú, siglo XIX.

\section{Sovereignty and Punishment in Charcas. \\ The Military and Judicial Repression of the La Plata and La Paz Juntas, $1808-1810$}

\begin{abstract}
The military repression of the juntas of La Plata and La Paz in 1810, as much as its judicial endorsement through convictions of diverse nature, referred to the resolution of a double intra-continental conflict of authority and jurisdictional influences: between viceroys and intendentes against other bodies like the audiencia; and between the viceroyalties of Río de La Plata and Peru. From the transformation of Charcas through violence into an insurance for the survival and conservation of viceroyal spaces, powers and capacities came the lost chance for a royal delegative institution -the audiencia- to legitimately assume undivided sovereignty, thereby fostering its dispersion through the cabildos.
\end{abstract}

Keywords: Violence, Sovereignty, System of Juntas, Military Repression, Judicial Process, Charcas, Audiencia, Cabildos, Viceroyalty of Río de La Plata, Viceroyalty of Peru, 19th. Century.

SUMARIO: 1. Introducción. 2. Castigo para las juntas. 3. La Junta de La Plata: refrendo popular y deshonor administrativo. 4. La Junta de La Paz: autonomía local y cadalso. 5. Conclusiones. 6. Referencias bibliográficas.

${ }^{1}$ Proyecto de investigación I+D: HAR2010-17580. 


\section{INTRODUCCIÓN}

La supresión de las juntas ${ }^{2}$ de La Plata y La Paz por las autoridades virreinales del Río de La Plata y del Perú tuvo una consistencia desigual. Mientras la primera se extinguió ante la amenaza de la fuerza armada y sus miembros sólo fueron objeto de "providencias preventivas" dirigidas "a conservar interinamente la quietud y la seguridad pública", la segunda fue disuelta por el ejército del brigadier José Manuel de Goyeneche, siendo sus principales miembros procesados y condenados a muerte por cometer un "delito de lesa majestad". Aunque la historiografía tradicional siempre ha aseverado el temprano carácter emancipador del experimento juntista, la diferencia en el trato y el castigo ha entronizado a la junta paceña como una experiencia liberadora superior, siendo aducida la naturaleza sangrienta de su represión como la prueba de su voluntad de independizar ${ }^{3}$.

Con el objetivo de reflexionar sobre la relación entre autoridad y soberanía en un contexto de ausencia real, se sostendrán dos hipótesis. En primer lugar, la represión de las juntas nada tuvo que ver con que fueran o no independentistas. El ejercicio de la violencia desde las sedes virreinales de Buenos Aires y Lima contra las iniciativas políticas de La Plata y La Paz enmascaró un conflicto intracontinental de poderes coloniales. No estaba únicamente en juego la autoridad de los virreyes frente a otros cuerpos como la audiencia, los cabildos municipal y eclesiástico o la universidad, sino que el control de Charcas se convirtió en un seguro de supervivencia y conservación de los espacios virreinales que obligó a una lucha de influencias jurisdiccionales entre éstos. En segundo lugar, si bien la represión de las dos juntas estuvo encaminada a impedir una redistribución de la potestad regia entre diversas instancias de autoridad, en términos de depósito de la soberanía fue mucho más grave el castigo dado a los responsables de la junta platense que el recibido por los de la paceña. Aunque no hubiese derramamiento de sangre, esa acción impidió la reconstitución del cuerpo político tal como se conocía hasta el momento. Es decir, la decisión de las fuerzas virreinales de condenar los esfuerzos de la junta de La Plata de impedir la disgregación de la soberanía convirtiéndose en el órgano superior de gobierno en Charcas tuvo, paradójicamente, el efecto adverso. Al negar a la audiencia la posibilidad de concentrar y arbitrar la soberanía, se perdió la posibilidad de que un órgano americano de amplia potestad y jurisdicción territorial, cuyo poder procedía de la delegación real, asumiera legítimamente la soberanía indivisa, favoreciendo la dispersión de la misma a través de los cabildos.

A partir de interrogantes sobre la diferencia y la intención del castigo sufrido por los juntistas de La Plata y La Paz, este artículo aborda algunas de las consecuencias que tuvo en la definición del cuerpo político de la futura Bolivia el ejercicio de la violencia virreinal contra las primeras juntas. Con ello busca valorar la importancia del ejercicio de la violencia en la generación de movilización social armada, en la resig-

${ }^{2}$ Para una visión historiográfica general del proceso juntista véanse los trabajos colectivos de Rodríguez, 2005; Chust, 2008; Ávila - Pérez Herrero, 2008; o Breña, 2010.

${ }^{3}$ Francovich, 1948; Abecia baldivieso, 1972, p. 15; Vázquez Machicado, 1991, pp. 39-41 y 112; JUST, 1994, p. 522. 
nificación de lo público y en la construcción de la legalidad. Ello implica partir de la premisa de que la violencia está presente en toda sociedad, que es un modo de acción social y que actúa como un instrumento de la política; lo que la capacita para fundar órdenes sociales y nuevas identidades públicas, acelerar o modificar la dinámica y los sistemas sociales y favorecer la cohesión social. Algo posible debido a que genera acciones relacionales que, al forzar la modificación de un comportamiento público, provocan una constante interacción social ligada inexorablemente al problema del poder ${ }^{4}$. Como la violencia se asume como un recurso disponible por los contendientes en un proceso destinado a frenar, acelerar o precipitar el cambio social o político, se va a subrayar el papel de la fuerza dictada contra las juntas por las autoridades virreinales. Su valor de acción de transformación política y pública provendrá de ser percibida por las corporaciones y la población como ilegítima por atacar o sofocar acciones no contrarias a la legalidad instituida e instruida por el cuerpo jurídico español. De hecho, Fernando VII expidió una Real Orden el 27 de junio de 1820 en la que reconocía que los procedimientos de los miembros de la Junta de La Plata habían sido dictados por la lealtad más acendrada "y el más recomendable celo en defensa de los derechos de S. M. y de la integridad de la nación", estableciendo que se diese satisfacción a los magistrados castigados ${ }^{5}$.

Como trasfondo de la discusión sobre la legitimidad y legalidad del uso de la violencia por parte de todos los actores implicados en la trama juntista se presupondrán cuatro apreciaciones historiográficas ${ }^{6}$. Primera, se ofrece una lectura de la emancipación charqueña ligada a un proceso de reajuste dentro de la monarquía española en el contexto de la revolución del mundo hispánico que activó las tensiones existentes entre España y sus territorios de Ultramar. A partir de esa visión general se quiere hacer especial hincapié en que las decisiones políticas y militares adoptadas estuvieron referidas a conflictos de autoridad y de jurisdicción entre las diversas instancias y cuerpos de poder virreinales y encaminadas, por tanto, a redefinir, a trastocar o a conservar un orden ${ }^{7}$. Segunda, siguiendo los postulados de José Luis Roca, lo ocurrido en La Plata y La Paz se asume como partes retroalimentadas de un mismo proceso cuyo detonante general fue la crisis de la monarquía española de 1808 y cuyo detonante particular fue el posterior intento de convertir al virreinato del Río de La Plata en un protectorado de la Corona portuguesa ${ }^{8}$.Tercera, la respuesta juntista charqueña se inscribió en la dinámica de conservar los derechos del rey legítimo, de su Corona y de sus dominios, y los derechos de los vasallos y de las corporaciones fuera del alcance de Napoleón o de la princesa portuguesa. En este sentido, ambas juntas no sólo tuvieron un origen único y nunca entraron en conflicto, sino que también poseyeron una continuidad institucional'. Por un lado, la Junta de La Plata necesitó, legitimó

\footnotetext{
${ }^{4}$ Sobre bibliografía consúltese la presentación al dossier.

5 "Real orden" reproducida en El Triunfo de la Nación. Lima, 16-II-1821.

${ }^{6}$ Sobre el desarrollo de la juntas bajo esos cuatro presupuestos véase IRUROZQUI, 2007 e IRUROZQUI, 2010.

${ }^{7}$ Se suscriben los planteamientos de: Guerra, 1995; RodríGuez, 1996; Annino, 2005, pp. 103-112.

${ }^{8}$ Roca, 1998, pp. 20 y 149; RocA, 2007.

9 Según lo afirmado por Mario Castro Torres, la tesis de la colaboración entre ambas juntas
} 
y potenció la existencia de la Junta de La Paz como parte de un sistema colegiado de juntas del que sería rectora. Por otro, ésta ratificó a la primera como el órgano hegemónico del espacio charqueño ante la acefalía real, asegurándose con ello su protección en la autogestión territorial de su entorno jurisdiccional urbano. Y, cuarta, las juntas se organizaron a partir de dos instituciones: la audiencia y el cabildo. La audiencia se consideraba depositaría de la soberanía en ausencia del monarca porque el carácter delegativo real de su poder la convertía en la instancia primera para asumir de manera unificada la potestad del reino, mientras que el cabildo lo hacía porque constituía el centro de poder de las sociedades locales en un contexto de inexistencia de Cortes americanas propias.

Tal acto representativo entrecruzaba dos concepciones de soberanía compatibles entre sí: unitaria y dispersa. La primera presuponía que en toda unidad política debía existir un poder último, indiviso y singular, con mayor autoridad legal que cualquier otro poder. La segunda estaba referida a que los derechos naturales del pueblo y de los pueblos al autogobierno podían volver a y repartirse entre ellos en caso de receso del soberano legítimo. El funcionamiento coordinado de ambos tipos de soberanía en tiempos de crisis remitía a la concepción contextual de "patria", de "patria amenazada" y de "patriota". A juzgar por los textos que circulaban entre 1808 y 1810 patria, más que remitir al concepto de nación moderna, hacía alusión no solo al lugar de residencia, sino principalmente a una comunidad de conciudadanos que habitaban un vasto e impreciso espacio y eran capaces de autogobernarse merced a la ligazón de los sujetos al medio local. Al tratarse patria de una noción inclusiva basada en los principios de igualdad de condición entre americanos y españoles peninsulares, de cooperación, de fraternidad, y de libertad, la patria amenazada estaba referida a los territorios de la monarquía puestos en peligro por las ambiciones de naciones extranjeras como Francia o Portugal, pudiendo ser considerados patriotas todos aquellos que se interesasen por el bien general, y contribuyeran a la defensa y conservación de todas las partes del reino. Tales actos de oposición y lucha contra la tiranía, sea cual fuera su origen y naturaleza, les hacían merecedores del ejercicio del autogobierno y de la autoridad, entendidos ambos en su dimensión de decisión y ejecución ${ }^{10}$. En este sentido, la participación generalizada de la población (o apoyo popular) en el proceso juntista debe verse ligada a su compromiso de salvaguarda del espacio local. Ello ocurría en un contexto de dislocación del entramado representativo en el que la defensa de los diversos intereses territoriales locales de Charcas se tornaba coincidente con la defensa de los intereses del rey español y en el que la autodefensa de la patria equivalía a salvaguardar a la monarquía.

quedaría también avalada en la nueva edición del Diario de los acontecimientos en la revolución de La Paz y relación de algunos anticipados hechos indicantes de ella, observados por un residente de esta ciudad desde el año de 1783 hasta el presente de 1810. Véase: CASTRO Torres, 2009, pp. 49-98.

${ }^{10}$ Acerca de estos conceptos y su polémica: IrURozQui, 2002 e IrURozQui, 2005. 


\section{CASTIGO PARA LAS JUNTAS}

E1 25 de octubre de 1809 el brigadier José Manuel de Goyeneche, tras dejar 2.500 soldados en el Alto, entró con una guarnición de 800 en la ciudad de La Paz, siendo alojado en el Palacio Episcopal. Bajo su autoridad, entre el 13 de noviembre de 1809 y el 26 de enero de 1810 tuvo lugar el juicio de los responsables del proceso juntista iniciado el 16 de julio de 1809 con las deposiciones de las principales autoridades y la posterior formación de un cabildo abierto que daría lugar a la Junta Tuitiva, a su Plan de Gobierno y a las proclamas paceñas ${ }^{11}$. Con la excepción del cura de Sicasica, José Manuel Medina, cuya ejecución quedó en suspenso por su estatus sacerdotal, fueron sentenciados a la pena capital nueve de los diez reos. Se les acusaba de querer introducir un nuevo gobierno y desarrollar "un plan de diez capítulos que atacaba las regalías de la soberanía, conspiraba destruir el legítimo gobierno e inducía a la independencia"12. El 29 de enero de 1810 tuvo lugar la ejecución. Pedro Domingo Murillo y Manuel Cossío, alias Mazamorra, fueron ahorcados; Juan Antonio Figueroa, Ventura Bueno, Basilio Catacora, Mariano Graneros, alias Challatejeta, Melchor Jiménez, alias Pichitanca, Apolinar Jaén, Gregorio Lanza y Juan Bautista Sagárnaga sufrieron garrote, siendo degradado militarmente este último del empleo de alférez delante de las banderas. El 3 de marzo el gobernador intendente interino de La Paz, Juan Ramírez, dictó sentencias de encierro y destierro para el resto de implicados, mientras que el 31 de mayo se confirmaba la pena de muerte para el cura Medina que debía realizarse en Lima ${ }^{13}$.

Aunque Goyeneche, ahora presidente de la Audiencia del Cuzco, y el gobernador de Cochabamba, José González de Prada, instaron al nuevo presidente de la Audiencia de Charcas, el mariscal de campo Vicente Nieto, a castigar a los miembros de la Junta de La Plata con la misma severidad que a los de La Paz, éste no siguió sus indicaciones y se mantuvo fiel a lo expuesto en su proclama de Jujuy del 28 de octubre de 1809. El 24 de diciembre Nieto entraba en la ciudad de La Plata. Dictó el embargo de bienes y de papeles y la prisión preventiva para los cómplices de la insurrección del 25 de mayo y los sucesos posteriores, y para todos los emisarios de la Junta. El argumento de la acusación fue haber atentado "atrevidamente contra la legítima autoridad del Jefe que gobernaba", arrogarse el mando y, con su mal ejemplo y con abuso de su potestad, contagiado

[...] a la desgraciada Ciudad de La Paz, sin omitir arbitrio de seducción y perfidia para envolver en su crimen a las demás Provincias en las que aunque no consiguieron el partido que solicitaban difundieron un mortífero veneno que no puede remediarse sino con los más ejemplares y extraordinarios castigos ${ }^{14}$.

\footnotetext{
${ }^{11}$ Sobre la polémica de las proclamas consúltese MendozA, 1997.

${ }^{12}$ Abecia baldivieso, 1972, p. 15.

13 Vázquez Machicado, 1991, pp. 39-41; Cotera, Tomás. Memorias históricas de la revolución política. Reproducidas en Ponce SAnginés, 1954a, p. 17I.

${ }^{14}$ Oficio del Presidente Nieto al virrey Hidalgo de Cisneros dándole cuenta de la detención de los reos de los sucesos de mayo. La Plata, 11-II-1810. Bando del presidente Nieto. Reproducidos en JUST, 1994, pp. 833-834 y 818-820.
} 
Fueron encarcelados Manuel y Jaime Zudáñez, Bernardo Monteagudo, N. Amaya, Joaquín Lemoine, D. N. Corcuera, Juan Antonio Fernández, los oidores Domingo Anivarro y Ángel Gutiérrez, el asesor Vicente Romano y el escribano de la Cámara de la Audiencia, Ángel Mariano Torres. Se ordenó al coronel Juan Antonio Álvarez de Arenales que se presentase en la capital del Virreinato para ser juzgado, siendo destituidos de sus cargos el fiscal Miguel López Andreu y los oidores José Agustín de Ussoz y José Vázquez Ballesteros y destinados, respectivamente, a las ciudades de Salta, Córdoba y Cuzco ${ }^{15}$. En ejercicio quedaron el conde de San Xavier y José Félix de Cantoblanco, aunque sus puestos de autoridad en el tribunal fueron ocupados de manera interina por Lorenzo Fernández de Córdova, relator jubilado, y por Antonio Caspe y Rodríguez, fiscal del crimen. El oidor honorario Pedro Vicente de Cañete, teniente asesor de Potosí, fue nombrado fiscal ${ }^{16}$.

Dada la diferencia del castigo sufrido por los participantes en las juntas de La Plata y La Paz se imponen tres preguntas: ¿qué pretendían las juntas?, ¿por qué las penas no fueron equivalentes? y ¿qué se quiso condenar en cada lugar?

\section{LA JUNTA DE LA PLATA: REFRENDO POPULAR Y DESHONOR ADMI- NISTRATIVO}

Conocidos por los miembros de la Audiencia los sucesos peninsulares y leída la carta de la princesa Carlota Joaquina de la Casa de Borbón en la que se ofrecía a tutelar Charcas en ausencia de su hermano y que había sido también entregada a los otros cuerpos charqueños entre el 19 y 20 de agosto de 1808 por Goyeneche, éstos optaron por "ignorar" lo comunicado. Al juzgar de "subversivo el contenido de dichos manifiesto" " 17 , a través del inmovilismo institucional habían buscado: primero, impedir un cambio de orden que rediseñase sus potestades locales; segundo, defender sus posiciones corporativas y de autoridad como funcionarios de la Corona; $\mathrm{y}$, tercero, evitar la posible dispersión de la soberanía o recuperar las soberanías dispersas para reafirmar precisamente esa situación de potestad ${ }^{18}$. Actuaron bajo el convencimiento de que la audiencia, al ser el órgano de máximo poder charqueño, poseía mayor autoridad legal que otros poderes para convertirse interinamente en ese poder último, indiviso y singular que debía existir en toda unidad política y, por tanto, ser la institución con mayor legitimidad para localizar temporalmente la soberanía. La fórmula que la audiencia encontró para preservar su legitimidad gubernativa como órgano central y centralizador de autoridad y garantizar la gobernabilidad del territorio fue

\footnotetext{
47-66.

${ }^{15}$ Sobre los emigrados de Charcas y su papel en la política rioplatense véase Aillón, 2008, pp.

${ }^{16}$ Oficio del Presidente Nieto al virrey Hidalgo de Cisneros dándole cuenta de la toma de posesión de la Presidencia de Charcas. La Plata, 10-I-1810. Reproducido en Just, 1994, pp. 828-830.

${ }^{17}$ La Plata, 25-V-1809. Archivo Histórico Nacional (en adelante AHN). Consejo, leg. 21348, 8, f. 2v; La Plata, 26-V-1809. AHN, Consejo, leg. 21342, 2, f. 2; La Plata, 26-V-1809. AHN, Consejo, leg. 21342,5, f. 447.

${ }^{18}$ IRUROZQUi, 2007, pp. 207-208.
} 
establecer bajo su liderazgo un sistema de juntas provinciales instaladas en las principales ciudades ${ }^{19}$. Para materializarlo debía asumir la totalidad de las funciones ejercidas antes por las autoridades reales, lo que sólo sería posible si las demás ciudades de su circunscripción le reconocían una hegemonía y una legitimidad incontestables. A fin de evitar que cada cabildo de otras urbes charqueñas asumiese la representación de su territorio urbano-rural y se constituyera en una unidad política autónoma, la Junta de La Plata desarrolló una estrategia de autopropaganda a la que le correspondieron dos acciones. Por un lado, la audiencia como gobierno autónomo de las cuatro intendencias creadas en 1783 -Chuquisaca, La Paz, Potosí y Cochabamba- debía ejercer su autoridad. El paso inicial de confirmación de la misma fue la notificación de lo sucedido a la Junta Central Suprema y Gubernativa y al virrey, dando ello lugar a un conjunto de oficios y vistas entre éste, el intendente de Potosí y los oidores a través de los que quedaba subrayada la potestad del tribunal ${ }^{20}$. Por otro lado, la audiencia determinó el envío de delegados a varias ciudades para que explicasen lo sucedido en la capital e informasen de su reasunción del mando político y militar y, así, lograr la adhesión de otras ciudades capaces de reasumir la soberanía y evitar que los carlotistas comenzasen un movimiento reaccionario ${ }^{21}$. En este sentido, expresiones referidas a que los emisarios chuquisaqueños buscaban "seducir a los Pueblos a igual revolución que la del veinte y cinco de mayo" incidían en que éstos tenían la misión de que los diversos territorios ratificaran la legitimidad del tribunal a la hora de deponer a su presidente por traición y asumir la dirección de Charcas por aclamación popular hasta que se aclarase la situación en la Península. La formación de una junta en La Paz fue interpretada, así, como una medida de acuerdo con lo ejecutado por el tribunal, que concebía necesario la administración del gobierno a través de una jerarquía de juntas provinciales.

Respecto a las intenciones virreinales que subyacían en la represión de la Junta de La Plata es necesario tener en cuenta los contenidos de los oficios intercambiados entre los meses de mayo y septiembre por los virreyes de Buenos Aires, Santiago de Liniers e Hidalgo de Cisneros, el gobernador intendente de Potosí, Francisco Paula Sanz, y sus subordinados y las diversas autoridades de La Plata. A partir de ellos se puede inferir de manera general que el principal objetivo de ambos virreyes era restablecer el orden jerárquico de autoridades preexistente a la acefalía real. Ahora bien, como las potestades del virrey sobre la audiencia habían sufrido por parte de los magistrados de ésta un cuestionamiento antiguo y continuo ${ }^{22}$, las medidas disciplinares dictadas desde Buenos Aires tenían la finalidad de fijar de modo unidireccional las capacidades jurisdiccionales y de autoridad del tribunal. Desde la perspectiva de un virrey, la actuación de los oidores contra el presidente, Ramón García de León y

${ }_{19}$ Posiblemente siguiendo el ejemplo de lo que había realizado la Junta Central Suprema y Gubernativa con las trece juntas provinciales peninsulares y que más tarde también trataría de hacer la Junta de Buenos Aires de 1810. Peralta, 2010, pp. 23-56.

${ }^{20}$ Buenos Aires, 27-V-1809. AHN, Consejo, leg. 21391, 17, f. 8; Colonia del Sacramento, 17-VII1809. AHN, Consejo, leg. 21391, p. 22, f. 77v.; Buenos Aires, 18-VI-1809. AHN, Consejo, leg. 21342, 5 , f. 23.

${ }^{21}$ Arnade, 1979, pp. 40-43; Roca, 1998, pp. 202-204.

${ }^{22}$ Just, 1994, pp. 30-33, 272-282. 
Pizarro, y el arzobispo, Benito María de Moxó y Francolí, la posterior constitución de una junta y las provisiones reales dictadas a otras autoridades de Charcas a fin de que acatasen sus decisiones suponían una insurrección interna en la jerarquía del poder en América. Para el control del territorio en un momento de crisis de la monarquía esto resultaba especialmente peligroso porque el sistema legal español permitía un disfrute compartido de competencias de poder y, por tanto, una posible atomización del mismo que derivase en la ruptura de la misma.

Ese funcionamiento se infiere de la actuación del intendente potosino frente a la Audiencia. Aunque, en un inicio se dirigió a La Plata en respuesta a la urgente demanda de auxilio de Pizarro por la destitución dictada contra él por los oidores, en ningún momento cuestionó la autoridad de éstos. Cuando escribió al virrey informándole de las razones que le obligaron a armar un ejército no señalaba que iba en socorro del presidente, sino "para ver si puedo proporcionar arbitrios de mediación, disponiendo los ánimos de modo que tal vez pueda tranquilizarlos y evitar lo más que pueda la necesidad de providencias estrepitosas" ${ }^{\prime 23}$. Esta actitud cautelosa no solo subrayaba que en un diferendo entre el presidente y los oidores su actuación contra alguno de ellos requería que instancias superiores autorizasen posibles actos de fuerza. También revelaba el reconocimiento de las potestades de la audiencia. Ésta, una vez reasumido el mando militar y político de Charcas, había dirigido una real provisión al intendente en la que le ordenaba la retirada del ejército bajo multa de 500 pesos por incumplimiento ${ }^{24}$. Orden que acató y que le permitió entrar en la ciudad para, por un lado, dar explicaciones sobre su llegada a "los señores ministros de este tribunal, individuos del ilustre ayuntamiento y otras diferentes personas de distinción de este pueblo", y, por otro, que éstos expusiesen las razones de su actuación contra Pizarro. A éste, los magistrados le acusaban de importarle más "conservar un mando que no puede desempeñar que conservar a la nación y al rey una honrada y estimable población", ya que su atención a la oferta portuguesa denotaba dos graves faltas: primera, entregar el territorio "inicuamente a una dominación extranjera"; y, segunda, no importarle el abandono del mismo yendo con ello en contra de su obligación, como "depositario de la seguridad pública", de velar por los intereses de Charcas.

Tal prueba de desafección a la patria no radicaba únicamente en las gestiones secretas de Pizarro referentes a hacer una "lista de proscripción por traidores" con todos aquellos que se oponían a la entrega de "estas provincias a una dominación extraña". Residía también en el empleo de las armas contra la población cuando ésta reaccionó en defensa de las víctimas de tal lista. Ciertos o falsos, los rumores de castigo a aquellos que se habían opuesto a los intentos de la Corte del Brasil de anexarse Charcas favorecieron que el 25 de mayo a las siete de la tarde se iniciase un movimiento popular destinado a evitar cualquier acto que atentara contra los oidores. La detención del abogado de pobres Jaime Zudáñez, acusado junto al resto de magistrados de conspirar para deponer a Pizarro, y la desaparición del fiscal López de Andreu provocaron "la ira del pueblo" contra el presidente. Con miras a tranquilizar los ánimos, el sub-

\footnotetext{
${ }^{23}$ Oficio del intendente de Potosí al virrey Liniers. Potosí, 26-V-1809. AHN, Consejo, leg. 21391, 22, f. 8.

${ }^{24}$ Auto de la Audiencia. AHN, Consejo, leg. 21391, 92, f.1
} 
delegado de Yamparaez, Álvarez de Arenales, en coordinación con los miembros de la audiencia le propusieron que atendiese las demandas del vecindario y le entregase "la artillería y fusilería depositadas en la Sala de Armas, situada en la misma casa de la presidencia", para su custodia en el patio del cabildo. Aunque en un inicio Pizarro aceptó, más tarde, temeroso de la acción popular, ordenó a sus soldados que disparasen a quienes exigían el armamento "respondiendo con bocas de fuego y granadas y tono insultante a la dulce expresión de viva Fernando VII". Ante un resultado de "muerte y heridas de muchos", la población vio en su "jefe a un enemigo declarado" e hizo uso de los pocos cañones que se habían entregado para resistir el "abuso de las armas del rey" bajo el grito de traición. A fin de evitar la ejecución popular de Pizarro, el tribunal forzó su dimisión y como representante único del rey asumió el mando de Charcas. La población aceptó el procedimiento y el resultado, porque el empleo de la fuerza por parte del presidente contra ella había sido interpretado como una prueba más de que el bienestar de los charqueños era "un problema secundario en la política de las autoridades superiores americanas". Se las desautorizaba a ejercer el mando por interpretarse su ejercicio de la violencia como un abuso ilegítimo e injustificable de autoridad. En contrapartida, el tribunal ganaba legitimidad porque la rendición de Pizarro y su posterior arresto en la universidad se interpretaron como un acto de obediencia de los oidores a las demandas del pueblo contra el presidente. Posteriormente, este resultado quedó ratificado públicamente cuando el retrato del rey fue colocado "en alto al frente de la plaza con doncel y colgaduras", mientras que el de Pizarro lo acomodaron "en unos palos que en figura de horca habían fijado en la plaza"25.

Conocedor de lo sucedido, el intendente Sanz fue consciente del peligro que corría su esfuerzo pacificador si se interpretaba que él había viajado a Chuquisaca para secundar a Pizarro en su actuación violenta contra el pueblo. De ahí que en todo momento sus acciones estuviesen dirigidas a no alarmar al vecindario y se esforzase en dar públicas explicaciones de su ida a la ciudad "al tribunal y al pueblo". El riesgo de "una guerra civil" se desvaneció en la medida en que el intendente reconoció primero, públicamente, y, más tarde, mediante un oficio al virrey, la potestad de la audiencia y el poder popular que la sustentaba:

[...] los efectos de ahora parece han acreditado lo justo de mis reflexiones y la unión de todo aquel cuerpo con los cuatro principales cuerpos, tribunal, cabildo y universidad componiéndose como se componen la parte principal y media de aquella ciudad de miembros y dependientes de ellos, y por consiguiente, adherir a éstos la plebe restante que en las circunstancias ha acreditado incontestablemente el mayor amor y veneración a los Sres. Ministros de aquella Audiencia únicos que en las actuales circunstancias han podido ahogar un incendio cuya voracidad llego al extremo de parecer inextinguible ${ }^{26}$.

${ }^{25}$ Informe del subdelegado de Yamparaez, Álvarez de Arenales. La Plata, 30-VI-1809. AHN, Consejo, leg. 21342, 3, f. 118; Vista del oidor fiscal D. Pedro Vicente Cañete sobre el origen y trascendencia de la conmoción del 25 de mayo de 1809. En Ponce Sanginés - García, 1953a, pp. CCXXX-CCLI.

${ }^{26}$ Oficio del intendente de Potosí al virrey. Potosí, 11-VI-1809. AHN, Consejo, leg. 21391, 23, f. 1 
Las palabras del intendente, los vítores populares "al rey y a la concordia entre Potosí y Chuquisaca" tras su conferencia con los oidores y el hecho de que asistiera a la procesión del Corpus, para que "el pueblo" quedase convencido de la "unión y conformidad de ideas" entre éste y el tribunal, redundaban en que las dos autoridades entendían de manera semejante la defensa de la patria. Si bien Paula Sanz siempre se esforzó en proteger a Pizarro, su principal objetivo fue establecer "el sosiego público". Y éste significaba ante todo el mantenimiento de la unidad territorial charqueña expresada en "el desarrollo de buenas relaciones entre Potosí y Chuquisaca" para evitar "catástrofes las más lastimosas y del mayor escándalo en el centro del Reino"27. Es decir, ante un problema de jerarquización de la autoridad en un contexto de crisis monárquica, el intendente y el tribunal coincidían en primar los intereses locales y, por tanto, reforzar el hermanamiento territorial frente a agresiones exteriores. Pero dicha concordia territorial implicaba también el reconocimiento por parte del intendente de la potestad que el tribunal podía ejercer sobre él; lo que quedó posteriormente expresado en considerar traidores al rey y a la patria a todos los que atentasen contra sus dictámenes ${ }^{28}$. Como señaló en numerosas ocasiones el fiscal de la Audiencia a los cabildos de Oruro y de La Paz, sólo debían ser obedecidas "las órdenes legítimas del superior gobierno actual y las de esta Real Audiencia a quien las leyes y el excelentísimo Sr. virrey le tienen comunicado el mando inmediato de estas provincias" 29 . La autoridad que el tribunal podía ejercer sobre Charcas fue, de hecho, reconocida por el intendente de Potosí y también por los virreyes rioplatenses cuando le pedían a la Audiencia que tomara medidas de orden frente a la junta paceña. Ante esa demanda, la Audiencia asumió su legítima potestad, pero no lo hizo en los términos esperados. Interpretó tal solución como "propia de las circunstancias", dejando claro a la junta paceña que su actuación gozaba de su beneplácito ya que ratificaba y expandía lo hecho por ella ${ }^{30}$. Fue tal la defensa de la misma que, ante la posibilidad de que el intendente desarrollase una acción armada contra La Paz, el fiscal le advirtió que de hacerlo iría en contra de las reales provisiones de la audiencia y "se le declarará traidor al rey y atentador contra la quietud pública", siendo castigado por todos "los cargos de excesos, desacatos, facultades usurpadas y ultrajadas". Con intención de asegurarse la obediencia que otros cuerpos debían a la audiencia, el fiscal mando oficios al cabildo de Potosí para que no cooperara con el intendente en los atropellos que éste dispusiese para soliviantar a "los Pueblos: amenazar a La Paz, insultar a Chuquisaca y no tener el menor miramiento a la V. A.". En todo momento, el argumento para la defensa de La Paz y de otras ciudades que la emularan fue que

${ }^{27}$ Informe de la Audiencia de Charcas al virrey Liniers. La Plata, 2-VI-1809. AHN, Consejo, leg. 21391, 22; Oficio del intendente de Potosí al oidor Vázquez de Ballesteros. La Plata, 30-V-1809. AHN, Consejo, leg. 21392, 83 f. 13.

${ }_{28}$ Autos y vistos de la Audiencia de Charcas. La Plata, 9-VIII-1809. En Ponce Sanginés, 1954b, segunda parte, pp. 458-459, nota 2.

${ }^{29}$ Vista del fiscal López de Andreu solicitando de la Audiencia una segunda Real Provisión contra el Intendente de Potosí. La Plata, 24-VIII-1809. AHN, Consejo, leg. 21391, 22, f. 81v.

${ }^{30}$ Oficio del virrey Cisneros a la Audiencia de Charcas. Buenos Aires, 11-IX-1809. AHN, Consejo, leg. 21391, 21, c. 2, f. 11; Real Provisión de la Audiencia al Cabildo secular de La Paz. La Plata, 9-VIII1908. AHN, Consejo, leg. 21391, 22, f.94. 
"el castigo de jefes delincuentes no es subversión del reino, ni falta de vasallaje, sino remedio contra la tiranía" 31 .

Aunque los dos virreyes, Liniers y Cisneros, firmaron sucesivos oficios en los que aceptaban provisionalmente el gobierno de la Audiencia, el castigo del que finalmente fueron objeto sus miembros incidía en que en la resolución del conflicto ganó el principio de jerarquización de la autoridad. Si bien, por ejemplo, Cisneros era consciente de la necesidad de conseguir consensos intra e interterritoriales traducidos en el establecimiento de decisiones políticas y militares únicas y compartidas, en su logro primaba el principio vertical y unidireccional del poder. Ello no solo se constató en la petición y en la aceptación de la intervención del virrey peruano en el desenlace de los acontecimientos, sino sobre todo en la respuesta dada al informe enviado por la audiencia para explicar sus decisiones. Instaba a que magistrados y ministros se unieran "con su jefe, olvidando resentimientos provenientes del desempeño de sus cargos que no deben ser trascendentales a las personas, ni servir de fomento a personalidades reprensibles". En anteriores ocasiones él y su antecesor habían tolerado "por el mejor servicio y tranquilidad del reino, atentados y desacatos que en otra época exigirían el más terrible escarmiento", pero la situación peninsular le impedía hacerlo ahora. Debía regir la "obediencia a las legítimas autoridades, la conservación del decoro y respetos debidos a la alta dignidad de este superior gobierno", de manera que todos "los tribunales y jefes de estos dominios" debían cumplir puntualmente las ordenes emanadas "del lugarteniente de su majestad e inmediato representante de su soberana autoridad".

En este sentido, el castigo recibido por los miembros de la Junta de La Plata obedecía a que éstos: primero, habían dejado que sus intereses corporativos primasen sobre la obediencia a un orden jerárquico superior representado por las cabeceras virreinales; segundo, habían obrado con susceptibilidad en la defensa de las potestades anexas a sus cargos por creer atropellada su autoridad por poderes superiores; tercero, en virtud de tales pruritos institucionales no sólo habían revocado y contravenido los dictados del virrey "sin tener la menor facultad", sino que habían hecho "alarde de desobedecerlas y de manifestar, siendo subordinada, una superioridad" de la que carecían; y, cuarto, habían defendido a través de la formación de una junta el espacio local charqueño sin tener en cuenta al respecto las posibles decisiones virreinales. En consecuencia, las condenas estaban dirigidas a disciplinarles en su calidad de funcionarios reales y a hacerles comprender un nuevo orden de autoridad dictado por las cabeceras virreinales ante la emergencia peninsular. Asimismo, debían ser escarmentados con la perdida de sus cargos y de la preeminencia social inherente, porque con su conducta indisciplinada habían dado ejemplo de insubordinación en las instituciones y entre la población. Al no "tener por las leyes la indispensable y forzosa obligación de guardar y hacer guardar y cumplir las providencias de este Superior Gobierno" habían "conmovido al pueblo" y alentado la rebelión popular, amparándose también en "la irritación del populado" para cuestionar la legalidad y legitimidad de los dictámenes virreinales. Ante ello, no les quedaba a los virreyes otra opción que

${ }^{31}$ Vista fiscal a los acontecimientos del 16 de julio en la ciudad de La Paz. La Paz, 9-VIII-1809. AHN. Consejo, leg. 21391, 22, f.46; Auto de la Audiencia por el que se manda librar una Real Provisión contra el intendente de Potosí. La Plata, 9-VIII-1809. AHN, Consejo, leg. 21391, 22, f. 57. 
restablecer mediante sentencia el diseño de la jerarquía de mandos, y clarificar quién ostentaba el poder último en suelo americano. De ahí el significado estratégico del nombramiento de Cañete ${ }^{32}$, antiguo asesor del expresidente Pizarro, como fiscal. No se trataba de una mera sustitución, sino de recordar a los oidores que el tribunal no estaba autorizado a reformar las disposiciones del virrey. En consecuencia se concedía un cargo de preeminencia justamente a uno de los personajes a los que la junta había culpado de generar un grave problema en ella porque de esta manera se subrayaba el origen del mando ${ }^{33}$.

Resultado final de todo ello fue la imposición militar del poder superior del virrey sobre la Audiencia, radicando la legalidad de la acción en un criterio de emergencia. Como ya se ha indicado, las penas se limitaron a encarcelamientos breves, destituciones y destierros porque se quería castigar la insubordinación de altos funcionarios sin que éstos pudieran ser vistos por la población como contrarios al rey y sin que su institución de referencia perdiese reconocimiento como fuente de autoridad. Por mucho que el virrey quisiese presentarse como el delegado más directo del monarca en ningún caso podía apelar a las leyes para ser reconocido como poder único ni para condenar a los oidores por traición a la monarquía. De ahí que el nuevo presidente del tribunal, Nieto, solo consintiese en impartir castigos por perturbación de "la quietud social" y no de "lesa majestad y traición". Sin embargo, el celo de los virreyes para conservar la unidad territorial de la monarquía y hacer primar su autoridad provocó lo contrario. La voluntad de la Audiencia de precautelar los derechos del monarca cautivo, mediante una red piramidal de juntas que reuniese "a todos los americanos a favor de una causa común" y, así, evitara "la brecha que se intentó contra la integridad de estos dominios" 34 , no fue bien recibida por las otras autoridades reales. Aunque éstas comprendían el peso institucional del tribunal, la represión que le infringieron imposibilitó su hegemonía regional y su propósito de frenar la dispersión de la soberanía en nombre del rey. Y esa soberanía indivisa tampoco la pudieron ostentar las cabeceras virreinales, porque los virreyes con su acción militar habían cuestionado la legitimidad institucional que podía emanar del sistema juntista, y más aún de una junta como la platense que justificaba su accionar en que era una institución delegativa real. Mantuvieron en los siguientes años la dirección del poder en América, pero no la soberanía real ni la soberanía popular.

\section{LA JUNTA DE LA PAZ: AUTONOMÍA LOCAL Y CADALSO}

Tras la toma del cuartel, el movimiento paceño del 16 de julio de 1809 iniciado durante la fiesta de la Virgen del Carmen, depuso, al igual que en La Plata, a las dos más altas autoridades en nombre de la defensa de la soberanía real: el gobernador intendente Tadeo Dávila y el obispo Remigio La Santa y Ortega. Para la formación de una junta se adujeron argumentos relativos a "sostener los derechos de la Corona,

\footnotetext{
32 Just, 1994, pp. 48-53.

33 Oficio de Liniers a la Audiencia. Buenos Aires, 10-VI-1809. AHN, Consejo, leg. 21391, 17, f. 11v.

${ }^{34}$ Carta de D. Diego de La Vega a Manuel Sudanés. AHN. Consejo. leg. 21392, 83, f. 117.
} 
la seguridad de la Patria y evitar las consecuencias dolorosas y amargas que verdaderamente se originarían de unas causas que ya se miraban tan inmediatas y próximas". Sin embargo, tales acciones y razones no podían ser recibidas por la población de igual modo que las esgrimidas por la audiencia, ya que el cabildo no poseía su mismo peso institucional. Como sus autoridades no estaban constituidas por el soberano, se tomó al tribunal como máxima instancia de autoridad. Atendiendo a ello, el 18 de julio de 1809 "los representantes del pueblo de La Paz" justificaron la destitución del gobernador intendente y del obispo debido a que ya no había "respeto, barrera, ni consideración que los contuviese en los deberes de su autoridad", manifestándose su criminalidad en el hecho de adherirse "a las injustas solicitudes de la Sra. Princesa del Brasil reconociéndola por soberana de estos dominios" y así trastocar "el orden político y la quietud pública". Como se temía una "conmoción popular cuyos resultados serían funestísimos para sus habitantes", para mejor oponerse a "la fuerza despótica de las dos autoridades" y a sus perversas maquinaciones se había decidido

[...] reunirse en masa, convocar a sus representantes y pedir la deposición del gobernador interino, y que el obispo pasase el gobierno de esta iglesia en el venerable presidente y cabildo eclesiástico y que se organizase un gobierno según el espíritu de nuestras sabias leyes y con adecuación al sistema de nuestra amada Península.

En consecuencia, puesto que reconocían la autoridad jurisdiccional y territorial de la Audiencia le pedían a ésta que tomase "las resoluciones que fueren de su superior agrado en las presentes circunstancias: en la inteligencia de que sus determinaciones se recibirán con el mayor respeto y consideración" 35 .

Con el fin de asentar los vínculos entre ambas ciudades, y tras la ida a La Plata de Julián Gálvez y Victorio García Lanza, que fueron recibidos con aplausos y aclamaciones por la población, se nombró posteriormente diputado para la ciudad de $\mathrm{La}$ Plata a José Antonio de Medina, quien debería ir allí con instrucciones "para que haga entender y manifieste a este regio tribunal e ilustre ayuntamiento los nobles sentimientos que han precisado a verificar el presente plan de gobierno", cuyas acciones respondían al "mayor interés de la patria y de los derechos de la Corona", y para la seguridad pública del pueblo. Tal nombramiento constituía una formalización del sistema de juntas, en cuyo diseño habían sido básicas las gestiones ya realizadas por el enviado de la audiencia a La Paz para hacer conocer su real provisión, el abogado Mariano Michel, quien en su trayectoria a dicha ciudad se había reunido con el mencionado Medina en Sicasica ${ }^{36}$.

\footnotetext{
${ }^{35}$ Informe de los representantes del pueblo de La Paz a la Audiencia de Charcas dándole cuenta de los sucesos del 16 de julio de 1809. La Paz, 18 de julio de 1809. AHN, Consejo, leg. 21392, 54, f. 10.

${ }^{36}$ Declaraciones de Melchor León de la Barra. Archivo General de la Nación Argentina (AGN). División Colonia, Sección Gobierno. Tribunales, Revolución de La Plata y La Paz, 25-V y 16-VII-1809. Proceso, cuadernos 1 al 4. Reproducidos en ABECIA BALDIVIESO, 1972, p. 76; Relación imparcial de los acontecimientos de la ciudad de La Paz en la noche del 16 de julio de 1809 y días sucesivos por Jorge de Ballivián, Agustín de Álava, Benito Blas de la Abariega, Pedro González Rubín y José de Mendizábal e Imáz. Reproducido en VázQuez Machicado, 1991, pp. 69-77.
} 
La hegemonía reconocida por los paceños al tribunal conllevaba también la existencia de otras fuerzas que podían considerarse por encima del cabildo "para ahogar cualquier alboroto", ya que sin la debida subordinación a las autoridades no era posible que subsistiese la tranquilidad pública ${ }^{37}$. Una de ellas era el intendente de Potosí. Aunque el virrey del Río de La Plata le había ordenado intervenir en La Paz, sabía que la Audiencia no iba a autorizarle a hacerlo, no siendo prudente por su parte ejercer acciones que atentasen contra "la conservación del sosiego de estas provincias". Convencido de que ello dependía "de la unión y conformidad de ideas" entre las diversas autoridades solicitó al tribunal el envío de "algún ministro" que hiciera una indagatoria judicial sobre el caso a fin de evitar "un contagio civil de provincia en

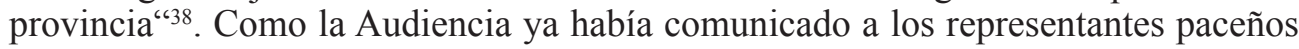
que quedaba enterada "del notable acontecimiento" y se disponía a iniciar una instrucción que lo aclarase ${ }^{39}$, contestó al intendente que estaba a la espera de la información que le ofrecieran tanto el cabildo de La Paz como el virrey Cisneros, por lo que le ordenaba que suspendiese las medidas que tenía proyectadas contra esa ciudad ${ }^{40}$.

Consecuencia del celo de la Audiencia en la defensa de sus potestades jurisdiccionales y territoriales fue la autonomía política de la junta paceña, siempre y cuando ésta actuase como una junta provincial dependiente de la de La Plata. Mientras ésta se mantuvo como centro del poder en Charcas, los paceños pudieron desarrollar sus proyectos de control local de sus recursos. Sin embargo, cuando el virrey del Perú decidió intervenir en aras de la protección de su espacio jurisdiccional, la situación varió y se produjo una militarización de los sucesos. Los procedimientos institucionalistas del intendente para obtener de modo pacífico la subordinación paceña a las respectivas autoridades fueron sustituidos por otros más expeditivos tendentes a asegurarse a través de la conquista de La Paz el control de Lima sobre Charcas y, con ello, la renuncia tácita, no formal, de Buenos Aires a la dirección de este territorio ${ }^{41}$.

El virrey del Perú, José Fernando de Abascal ${ }^{42}$, había tenido noticias por varios frentes y al mismo tiempo de los movimientos de La Plata y La Paz. Puesto inmediatamente en contacto con las autoridades fronterizas de su virreinato, con el virrey de Buenos Aires y el intendente de Potosí, fue informado de la actitud hegemónica de la audiencia. Ésta se asumía como único órgano de gobierno en Charcas y como tal desautorizaba cualquier actuación militar, ordenaba al resto de provincias que solo acatasen provisiones ratificadas por ella y defendía a la Junta Tuitiva. Aunque

${ }^{37}$ Oficio del intendente de Potosí al cabildo de La Paz. Potosí, 25-VII-1809. AHN, Consejo, leg.. 21391, 22, f. 26v.

${ }^{38}$ Oficio del intendente de Potosí a la Real Audiencia. Potosí, 25-VII-1809. AHN, Consejo, leg. 21391, 22, f. $28 \mathrm{v}$.

${ }^{39}$ Auto de la Audiencia. AHN, Consejo, leg. 21392, 54, f. 8.

${ }^{40}$ Oficio del semanero al intendente de Potosí. La Plata, 29-VII-1809. AHN, Consejo, leg. 21391, 22, f. 32.

${ }^{41} \mathrm{Al}$ respecto no debe de olvidarse que en el proceso contra los reos paceños intervinieron magistrados de la Audiencia de Lima. Ello no solo implicaba una afrenta para los miembros de la Audiencia de Charcas, sino que también implicaba la reasunción del gobierno de ésta por parte de virreinato peruano. Autos de confesión. En Ponce Sanginés - García, 1954b, pp. 83-86.

${ }^{42}$ Sobre la política del virrey Abascal consúltense en extenso Peralta, 2002 y Peralta, 2010. 
solucionar los dos movimientos competía al virreinato rioplatense, la situación de fragilidad de Cisneros $^{43}$ en el mando y la mayor proximidad a las zonas de conflicto de las fuerzas peruanas favoreció que el primero incurriera en un acto de "dejación de autoridad" y que Abascal dirigiera sin conflicto de competencias y con su beneplácito toda la operación. Ello tuvo una triple consecuencia.

Primero, aunque Buenos Aires había aceptado de modo provisional la capacidad gobernadora del tribunal en el oficio de Liniers del 18 de junio de 1809 y en el de Cisneros del 17 de julio de 1809, señalándose que mientras se nombraba un nuevo presidente para la Audiencia se obedeciesen sus órdenes en lo que no fueran "contrarias a las de esta Superioridad" ${ }^{44}$, Abascal desestimó de facto tal hegemonía. Los sucesos charqueños constituían una amenaza directa tanto a su poder como alter ego del monarca, como a la integridad territorial de su virreinato. En un inicio, temía que el fenómeno juntista se esparciese por este, sobre todo porque La Paz había enviado emisarios a Puno, Cuzco y Arequipa con el posible fin de ampliar la constelación juntista diseñada por los oidores chuquisaqueños ${ }^{45}$, importándole más tarde las consecuencias que pudiera desencadenar la sumatoria de la junta quiteña del 10 de agosto a las charqueñas debido a que el virreinato peruano corría el riesgo de quedar aislado.

Segundo, el escaso interés de los peruanos en respetar desde un inicio la potestad gubernativa del tribunal afectó negativamente a la supervivencia institucional de la Junta Tuitiva. Como ésta había basado sus actos en la aquiescencia de la Audiencia, la desautorización del virrey hizo que las decisiones paceñas en defensa del monarca se tornasen en criminales delitos contra las autoridades constituidas por este ${ }^{46}$.

$\mathrm{Y}$, tercero, en las ciudades juntistas fueron desatendidos los resultados del proceso representativo orquestado por la Junta Central Gubernativa por la Real Orden de enero de 1809 para elegir diputados para la misma. Liniers había enviado instrucciones al respecto a los cabildos cabeceras en una circular fechada el 27 de mayo de 1809, siendo la orden complementaria de la Junta Central de 6 de octubre de 1809 la que ratificó que todos los cabildos pertenecientes o no a ciudades cabeceras podían participar en la elección. Si bien, para el momento en que se disolvía la Junta Central ya habían sido electos representantes por Potosí, Santa Cruz y Mizque, las actuaciones realizadas en La Plata y La Paz se leyeron comos actos de sedición y como tales fueron descalificadas ${ }^{47}$.

43 Como indica Marcela Ternavasio era el primer virrey cuyo nombramiento no emanaba directamente del rey sino que había sido designado por la Junta Central el 11 de febrero de 1809, siendo su prioridad reinstalar el prestigio de la autoridad virreinal en una ciudad expuesta a "una revolución de virrey". TernaVasio, 2009, pp. 62-63; TernaVasio, 2010, pp. 274 y 276.

${ }_{44}$ Oficio del virrey Liniers al intendente de Potosí. Buenos Aires, 18-VI-1809. AHN, Consejo, leg. 21342, 5, f. 23. Oficio del virrey Cisneros autorizando a la Audiencia de Charcas. Colonia de Sacramento, 17-VII-1809. AHN, Consejo, leg. 21391, 22, f. 77v.

45 Autos de confesión. En Ponce Sanginés - García, 1954b, p. 87; Sobre la participación de Cochabamba véase Solicitud del Título de fiel constante leal Villa de Irupana al virrey Abascal. Archivo General de Indias (AGI), leg. 742, 308, f.1.

${ }^{46}$ Díaz Venteo, 1948, pp.43-79.

47 Ternavasio, 2009, pp. 59-61; Ternavasio, 2010, pp. 287; Ponce Sanginés - García, 1953, vol. I, pp. CLVIII-CCVIII. 
El plan militar de Abascal consistió en el reclutamiento y adiestramiento de un ejército formado por personal de los territorios sureños del virreinato peruano a cuyo cargo debía ponerse el intendente de Huarochirí, Juan Ramírez. Dada la premura de las circunstancias fue Goyeneche quien dirigió estas tropas. Al tiempo que se desarrollaban los preparativos militares, el brigadier no dejó de comunicarse con La Paz, existiendo momentos en los que parecía que iba a ser posible una solución pacífica del conflicto ${ }^{48} \mathrm{y}$, en consecuencia, primar el principio de que mejor era "agotar todos los medios que pudiese sugerir la más acreditada prudencia" que llegar "al uso recíproco de las armas y el triste fin de una guerra civil"49. Sin embargo, la urgencia para restablecer la autoridad virreinal decidió al brigadier intervenir en la ciudad de La Paz para que "se aniquilen y exterminen, sin perjuicio y detrimento de ninguna clase de ese leal vecindario, todas las facciones y dislocaciones de que Uds. son testigos y yo me halle cerciorado", dando lugar la proximidad de su ejército a un recrudecimiento de las disputas internas y a un exacerbamiento de las posiciones. Esto último quedó expresado en la petición pública del 12 de septiembre de 1809 a los "Sres. de este ilustre cabildo, justicia y regimiento, gobernador intendente" para que se pronunciasen ante las hostilidades de la intendencia de Puno contra La Paz. Tras una discusión destinada a establecer sus intenciones, se acordó declararles "invasores y enemigos" por "traidores a la causa del soberano y la patria". También se decidió comunicarlo a la audiencia, ya que se la reconocía autorizada por el virrey Cisneros "para entender en todo lo concerniente a la quietud y sosiego de todas estas provincias interiores". Además dicho virrey había aprobado "todos los acontecimientos del 25 de mayo próximo pasado de la ciudad de La Plata y en virtud de esta decisión haberse librado por aquel superior tribunal dos reales provisiones con el objeto de que ningún pueblo ni provincia levante armas contra la ciudad de La Plata y ésta de La Paz". Como el intendente de Puno agredía a La Paz, este había "hollado las altas representaciones y facultades de excmo. virrey de estas provincias y de la Real Audiencia del distrito" 50 .

Fracasado el proceso de negociaciones entre Goyeneche y la Junta Tuitiva devino la derrota militar de ésta, quedando subrayado que para el primero la defensa de la patria y de Fernando VII significaba que la máxima autoridad en América era el virrey sin que la soberanía pudiera pasar nunca al pueblo, mientras que para los juntistas la defensa del monarca y el mantenimiento "de la quietud pública" equivalía a actuar a favor de los intereses del espacio paceño. En consecuencia, el anunciado "perdón a nombre del rey" del 25 de septiembre de $1809^{51}$ se tornó en un proceso criminal, cuya orden de ejecución, aunque llegó de Buenos Aires para "la formación del proceso, averiguaciones del enorme delito de sedición y sus autores y finalmente para castigar-

\footnotetext{
${ }^{48}$ Véase la conferencia en el Desaguadero protagonizada por Goyeneche y una diputación paceña, octubre de 1809 en Díaz Venteo, 1948, pp. 69-70; Abecia Baldivieso, 1972, pp. 14-15; Correspondencia entre Pedro Murillo, Francisco Paula Sanz y José Manuel de Goyeneche. En Ponce SAnginés, 1954b, segunda parte, pp. 347-375; RIVERA, 1972, pp. 113-147.

49 ABASCAL, 1944, vol. II, pp. 9-10.

${ }^{50}$ Declaratoria de guerra a Puno, firmada por el cabildo el 12 de septiembre de 1809. En PonCE SANGINÉs, 1954b, segunda parte, pp. 451-462.

${ }^{51}$ Ponce SAnginés, 1954b, segunda parte, pp. 463-467.
} 
los ejemplarmente", fue informada por Abascal ${ }^{52}$. El auto sumario se inició el 23 de diciembre con declaraciones de seis personas que no estuvieron ligadas al movimiento, procediéndose el 5 de enero de 1810 al edicto de prisión. Al día siguiente se empezaron a tomar las confesiones. La acusación del fiscal tuvo lugar el día 11, siendo nombrado el 15 el defensor de los acusados. Las ratificaciones de las declaraciones preventivas y las confesiones continuaron hasta que el día 23 los testigos expusieron a favor de los reos, apareciendo la primera sentencia el 27. Como ya se ha indicado, los diez culpados de "de alta traición, infames aleves y subversivos del orden público" fueron condenados a muerte ${ }^{53}$. ¿Qué se quiso castigar con este proceso?

$\mathrm{Al}$ respecto este texto suscribe lo expresado por Javier Mendoza referente a que el proceso mencionado "fue una mera formalidad, un acto para llenar los requisitos jurídicos necesarios que antecedieron y justificaron las ejecuciones", siendo la naturaleza subversiva del Plan de Gobierno una construcción discursiva de las autoridades virreinales $-\mathrm{y}$ no de las peninsulares- elaborada durante el proceso ${ }^{54}$. Aunque se acusó a los reos paceños de "síntomas de una verdadera anarquía bajo el velo de amor al rey" 55 , de "aprovecharse de este tiempo de turbulencia y aflicción y separarse de la metrópoli" ${ }^{56}$ y se les adujo un delito criminal de lesa majestad, nunca renegaron de haber actuado en "defensa de la soberanía real", defendiendo que sus actos no fueron "los feos borrones de la insubordinación contra las autoridades", sino efecto de su patriotismo. Luego el problema estribaba en que no era compartida entre los diversos cuerpos americanos una única manera de precautelar los derechos del monarca ante la invasión francesa. Tal como consta en los diez estatutos del Plan de Gobierno, para la Junta paceña la defensa de los intereses de Fernando VII implicaba "atender a las necesidades" de la patria local "contra las injustas pretensiones de la Princesa del Brasil y de las seducciones con que las potencias extranjeras pueden conmover los ánimos de sus habitantes con el fin de que divididas en facciones o en partidos las numerosas provincias que forman el cuerpo respetable de la América se ataque la integridad y seguridad de estos dominios", siendo el resultado "la confusión, el desorden y últimamente, su ruina fatal". En consecuencia, para evitar que el bienestar local fuese amenazado había que dejar de remitir numerario a "Buenos Aires de las Cajas Reales ni de ningún otro ramo como son los productos de las administraciones de correo y de tabaco"; mantener el circuito mercantil de la ciudad y la provincia de La Paz porque de la no defensa del comercio local nacería el desorden; armar a "todos los vecinos para defender y sostener los derechos de la patria"; asumir todas las competencias en materia de contribución; destituir y nombrar nuevos funcionarios;

\footnotetext{
${ }^{52}$ Abascal, 1944, vol. II, p. 48.

${ }^{53}$ Sobre el proceso y su procedimiento véase BARRAGÁn, 2006, pp. 172-173. Sobre la excomunión de los reos véase Pena GonZÁlez, 2011, pp. 523-538.

${ }^{54}$ MendozA, 1997, pp. 218-225.

${ }^{55}$ Oferta de Goyeneche. En Ponce SAnginés, 1954b, segunda parte, p. 463.

${ }^{56}$ Relación imparcial de los acontecimientos de la ciudad de La Paz en la noche del 16 de julio de 1809 y días sucesivos por Jorge de Ballivián, Agustín de Álava, Benito Blas de la Abariega, Pedro González Rubin y José de Mendizábal e Imáz. Reproducida en VázQuez Machicado, 1991, p. 67.
} 
ampliar el número de subdelegados; y dar representación a la población indígena, estando "apoyado este proyecto en el sistema de nuestra amada Península"s7.

Las mencionadas atribuciones en materia de gestión, seguridad, contribución y representación, unidas a los iniciales actos de destitución de autoridades fueron leídas por las cabeceras virreinales como un cuestionamiento del orden social imperante respecto a las relaciones de subordinación institucionales y a las jerarquías de autoridades. De manera que una vez que la Audiencia dejó de ser la institución superior que autorizaba a la Junta de La Paz a ejercer tales prerrogativas pertenecientes a la soberanía real, sus actos de "posesionarse de los empleos sin finanzas y sin ninguna de las formalidades prescritas por su majestad" o de "inquietar con lisonjeras ideas a la indiada" 58 fueron interpretados como atentados contra el monarca. Es decir, se castigaba a los juntistas por asumir el gobierno de su espacio local. Esta intención estaba recogida en la Relación imparcial de los acontecimientos de la ciudad de La Paz en la noche del 16 de julio de 1809 y días sucesivos, realizada por algunos vecinos contrarios a la junta:

Si los franceses [dicen] dominan la España parece ser consiguiente que alguno de la familia Real se traslade a esta América y establezca su solio en Lima y Buenos Aires, y como de este principio resultaría el engrandecimiento únicamente de la ciudad donde resida la Corte y absorbiéndose ésta las riquezas de las provincias interiores, nunca éstas saldrían del estado de inercia y abatimiento en que se hallan. Conviene [añaden] suceda o no el caso de dominación francesa preparar y disponer los pueblos al intento de que las provincias del Perú se declaren por confederadas independientes y a La Paz por capital de ellas para que así obtenga entre las ciudades del mundo el lugar y representación célebre de una Berna ${ }^{59}$.

El miedo a la pérdida de la autogestión territorial en favor de cuerpos ajenos o desconocedores de las necesidades de desarrollo y bienestar local quedaba también expresado de un modo más radical en la carta del 5 de noviembre de 1809 de Victorio García Lanza a Goyeneche. En ella consideraba que la defensa de la Península "de la ajena dominación" y "de las acechanzas enemigas" dependía de que las provincias americanas establecieran "los medios más propios y aparentes", como, por ejemplo, "quitar el mando a los europeos con el justo recelo que las intrigas siempre han sido hechas por ellos". Sólo así "exenta de la introducción de enemigos, se mantendría ilesa para conseguir la gloria de guardarla y conservarla para su legítimo dueño el Sr. D. Fernando Séptimo y presentársela luego que se verifique la restauración de su Trono". Y como prueba instaba a Goyeneche a que tomase "el mando y gobierno de toda la América", ya que en calidad de compatriota americano e hijo de la patria americana sería el más adecuado para "levantar este patrio suelo abatido, ultrajado,

${ }^{57}$ Estatutos del Plan de Gobierno del 21 de julio. Ponce Sanginés, 1954b, segunda parte, nota 1, pp. 451-457.

${ }^{58}$ Cotera, Tomás. Memorias históricas de la revolución politica. Reproducidas en Ponce SAnginés - Garcia, 1954b, pp. 37-38 y 80-81; VÁzquez Machicado, 1991, pp. 82-85.

${ }^{59}$ Cotera, Tomás. Memorias históricas de la revolución política. Reproducidas en Ponce SANGinés - Garcia, 1954b, pp. 85-86. 
envilecido y menospreciado de naciones extranjeras" ${ }^{\prime 60}$. Esta declaratoria autonomista de Lanza, más allá del oportunismo que implicaba la oferta a Goyeneche, remarcaba el vínculo entre poder político y preocupación por la patria local, siendo la naturaleza americana de la población la que determinaba su responsabilidad en la gestión del espacio territorial. De hecho, tal opinión también era compartida por muchos de los detractores de la junta. En la citada Relación imparcial, sus autores reconocían que lo sucedido en La Paz, además de ser consecuencia "del mal ejemplo de La Plata en la deposición de su presidente", lo había sido también de "la indolencia y abandono" del intendente Dávila. Al subrayar su desinterés por los asuntos de seguridad de la ciudad, le estaban culpando de haber puesto en peligro su posición colectiva dentro de la comunidad paceña. Tras los sucesos del 16 de julio los europeos de la ciudad habían sido obligados a jurar públicamente su fidelidad al monarca " $\mathrm{y}$ hacer causa común con los americanos". Como la mayor parte de ellos eran "avecindados", con "mujer, hijos, familia y relaciones de familia" y poseían "bienes raíces", tal gesto les molestaba no solo porque se había dudado de su patriotismo y fervor al monarca, sino también porque se había puesto en entredicho su enraizamiento local. Es decir, la negligencia con la que las autoridades habían afrontado la propuesta portuguesa y la preocupación del vecindario al respecto había hecho peligrar la comunidad constituida por "americanos y europeos avecindados", quedando demostrado también que en la determinación del bienestar público nunca primaban los intereses locales de ambos grupos, sino el de un poder superior indeterminado que podía ser contrario a los primeros ${ }^{61}$.

En este sentido, frases como que todos los miembros de las juntas iban a "un mismo fin con los de Chuquisaca", a "sacudirse el yugo de la nación española y [a] librarse de tantos robos que les hacía el rey" no significaban necesariamente soluciones independentistas respecto a España. El "yugo de la nación española" hacía referencia a la forma en que las autoridades virreinales atendían los asuntos charqueños dejando que sus intereses corporativos, de jerarquía y de autoridad primasen por encima del bienestar local y se impidiera "el adelantamiento de los reinos" ${ }^{2}$. La reacción del gobernador y el obispo a la oferta portuguesa sintetizaba, por tanto, el extrañamiento del vecindario paceño "en su propia patria", siendo la respuesta juntista la negación a que esto sucediera. De un lado, la acusación a sus protagonistas de atentar contra los atributos de la soberanía por deponer y elegir autoridades, tener armas, adueñarse de bienes o convocar gente, basándose en las proclamas y anónimos que circularon por Charcas pero que nunca fueron firmados por los condenados, y, de otro, los comentarios de Abascal referentes a "que la malicia de los autores del alboroto inventaba cada día muchos artificios para dilatar el debido reconocimiento a las autoridades, restablecimiento del orden y tranquilidad pública", resumieron no una acción de in-

${ }^{60}$ Carta reproducida en VÁzquez Machicado, 1991, pp. 27-28.

${ }^{61}$ Vázquez Machicado, pp. 69-77; Confesión de Tomás Domingo de Orrantia. La Paz, 15-I-1810. Reproducida en Ponce SANGinés - García, 1954b, pp. 740-741.

${ }^{62}$ Declaraciones de Agustín de Azcue, de José Guzmán, de Antolín Jiménez, Juan de Dios Jover y Juan Villarroel en el expediente del regidor de La Paz Manuel Victorino Lanza. Cochabamba, VII/ VIII-1809. AHN, Consejo, leg. 21392, 83, f. 41ss. 
dependencia sino un relato fidelista sobre ésta. Destinado a asentar el cuerpo supremo de autoridades en un momento en que la debilidad del monarca lo podía poner en entredicho, dicho discurso tildó de "ilegal gobierno" al autogobierno local y de "trastorno del gobierno legítimo por un pueblo tumultuado" ${ }^{63}$ a la legítima precautelación juntista de la soberanía del rey puesta en peligro por los carlotistas. Desautorizada la Audiencia de Charcas e ignorada la legítima competencia de sus magistrados para administrar el proceso judicial paceño, tales esfuerzos dirigidos "a la defensa de la patria, sagrados derechos de la religión y de la Corona" se tornaron en proyectos de "subtraer esta provincia y las inmediatas del suave dominio de la Monarquía"64.

\section{CONCLUSIONES}

En todo el conflicto protagonizado por las Juntas de La Plata y La Paz subyacía un problema básico: una crisis de autoridad en diversas instancias cada una correspondiente a las distintas dignidades americanas. Ésta dio lugar a un problema de legitimidad gubernamental que implicaba, por un lado, un riesgo de dispersión de la soberanía, y, por otro, una amenaza de remodelación de la jerarquía de autoridades. De todo ello fueron conscientes los diferentes cuerpos e instancias de gobierno, tratándolo de subsanar de diversos modos. Las destituciones de autoridades acusadas de traición, las juntas, las exigencias de sumisión institucional y los procesos represivosjudiciales ejecutados por los virreyes fueron cuatro de sus modalidades. Mientras las dos primeras estuvieron encabezadas por cuerpos colegiados como la Audiencia, los Cabildos civil y eclesiástico o la universidad, la tercera y cuarta fueron lideradas por los máximos agentes individuales de poder en América, virrey e intendente. En los cuatro casos se trató de precautelar los derechos del monarca, resultando de ello dos fenómenos: la reivindicación institucional y popular de la soberanía y el abuso de autoridad.

Como el juntismo implicaba un desplazamiento y cuestionamiento de las potestades de los virreyes, éstos negaron a través de la fuerza militar, los procesos judiciales, las sentencias y la autoridad gubernativa de la audiencia y el cabildo. Con ello hicieron consciente a la población charqueña de su vulnerabilidad legal y social. Si antes del proceso juntista la defensa del monarca equivalía a la defensa de sus espacios, estatus e intereses locales, invalidado el mismo por las armas y la justicia, tal salvaguarda regional podía significar un crimen de lesa majestad, siendo agentes no implicados con el medio local los encargados de determinarlo. Pero la dura represión que sufrió la Junta de La Paz frente a lo benigno de lo experimentado por la de $\mathrm{La}$ Plata no debe aducirse a que se la juzgó autora de un movimiento independentista que tenía su origen "en el mal ejemplo que dio el Tribunal de Charcas"65. Si bien ambas represiones respondieron a un ejercicio disciplinario por parte de las cabeceras virreinales y se insertaron en un contexto de competencia entre los virreinatos del Río de La Plata y del Perú, su discurrir estuvo ligado a la naturaleza de las instituciones que

\footnotetext{
${ }^{63}$ ABAscal, 1944, vol. II, pp. 9-10; 31-33.

${ }^{64}$ Interrogatorio, autos de confesión. Reproducidos en Ponce Sanginéz - García, 1954b, p. 85.

${ }^{65}$ Oficio de Goyeneche al Presidente Nieto. La Paz, 20-XII-1809. AHN, Consejo, leg. 21392, 83, f. 22.
} 
sostenían a las dos juntas: Audiencia y Cabildo. Si atacar al tribunal chuquisaqueño implicaba una desarticulación fidelista de una institución real, en el caso paceño no se planteaba necesariamente ese problema ya que el municipio no poseía el mismo peso institucional al carecer de la dimensión delegativa del monarca. Por tanto, aunque los miembros de ambas juntas fueron encausados, solo los de La Paz fueron acusados de querer la "sustracción de la monarquía" y castigados en consecuencia a la pena capital. La gravedad de esa sentencia ha desdibujado el significado que tuvo la negación de la capacidad de la Audiencia para instituirse en una junta ostentadora de la soberanía indivisa del rey y articuladora del territorio charqueño a través de un sistema de juntas provinciales subordinadas. Desdeñada su doble legitimidad -proceder de una institución delegativa real y ejercer el poder "por aclamación popular"- no solo se dio paso a la fragmentación de las soberanías al desaparecer el único cuerpo que podía contenerlas, sino que quedó sobredimensionada la capacidad del cabildo como entidad depositaria de soberanía.

La invalidación de las juntas formadas en 1809 mostraba, por tanto, como la autoridad de los virreyes se sobreimpuso a la de las juntas en su esfuerzo paralelo de restaurar una soberanía indivisa. Aunque éstos no violaron la ley al hacerlo, sí vulneraron la legalidad en el sentido de que se impusieron por la fuerza a actuaciones institucionales que también habían obrado conforme al derecho español, dando lugar a un abuso de autoridad que pudo abrir un camino a la emancipación. De ahí que la fragmentación de la soberanía resultase en gran medida del esmero con que las diferentes autoridades reales habían tratado de conservar su autoridad y espacios de acción, siendo los roces institucionales una fuente de pérdida de legitimidad gubernamental.

\section{REFERENCIAS BIBLIOGRÁFICAS}

Abascal y Sousa, Fernando de

1944 Memoria de gobierno. Edición de Vicente Rodriguez Casado y José Antonio Calderón Quijano. Sevilla. EEHA.

Abecia Baldivieso, Valentín

1972 Adiciones documentadas sobre Pedro Murillo. La Paz. Burillo.

AILLÓn, Esther

2008 "Los emigrados alto-peruanos de la guerra de independencia: patricios, españoles y guerrilleros". Anuario de Estudios Bolivianos, Archivisticos y Bibliográficos. Sucre. $\mathrm{n}^{\circ}$ 14, pp. 47-66.

AnNINo, Antonio

2005 "El paradigma y la disputa. La cuestión liberal en México y la América hispana". En Colom, Francisco (ed.). Relatos de nación. La construcción de las identidades nacionales en el mundo hispánico. Madrid Frankfurt. Iberoamericana y Vervuert, pp. 103-112. 
ARnade, Charles

1979 La dramática insurgencia de Bolivia. La Paz. Juventud.

Ávila, Alfredo y Pérez Herrero, Pedro (comps.)

2008 Las experiencias de 1808 en Iberoamérica. México. Universidad de Alcalá - Universidad Autónoma de México.

BARRAGÁn, Rossana

2006 "Los discursos políticos de la represión: una comparación entre 1781 y 1809". Secuencia. Revista de Historia y Ciencias Sociales. México. Número conmemorativo, pp. 165-198.

BREÑA, Roberto (ed.)

2010 En el umbral de las revoluciones hispánicas: el bienio 1808-1810. Madrid-México. El Colegio de México - Centro de Estudios Políticos y Constitucionales.

CAstro Torres, Mario

2009 "La manipulación del Diario de los acontecimientos en la revolución de La Paz". Anuario de Estudios Bolivianos, Archivísticos y Bibliográficos. La Paz. nº 15, pp. 49-98.

Chust, Manuel (ed.)

2008 1808: la eclosión juntera en el mundo hispano. México. Fondo de Cultura Económica.

Díaz Venteo, Fernando

1948 Las campañas militares del virrey Abascal. Sevilla. EEHA.

Francovich, Guillermo

1948 El pensamiento universitario en Charcas y otros ensayos. Sucre. Universidad San Francisco Javier.

GuERRA, François-Xavier (dir.)

1995 Revoluciones hispánicas. Independencias americanas y liberalismo español. Madrid. Ed. Complutense

IRUROZQUI, Marta

2003 "El sueño del ciudadano. Sermones y catecismos políticos en Charcas tardocolonial”. En Quijada, Mónica - Bustamante, Jesús (eds.). Elites intelectuales y modelos colectivos. Mundo Ibérico (siglos XVI-XIX). Madrid. CSIC, pp. 215-249.

2005 "De cómo el vecino hizo al ciudadano en Charcas y de cómo el ciudadano conservó al vecino en Bolivia, 1808-1830". En RodRíGuez O. (ed.), pp. 451-484.

2007 "Del Acta de los Doctores al Plan de Gobierno. Las Juntas en la Audiencia de Charcas (1808-1810)". En Chust (ed.), pp. 207-208.

2010 "La sombra del reino. El proceso juntista en la Audiencia de Charcas (1808-1810)”. En BREÑA (ed.), pp. 193-234. 
Just, Estanislao

1994 Comienzo de la Independencia en el Alto Perú: los sucesos de Chuquisaca 1809. Sucre. Ed. Judicial.

MendozA, Javier

1997 La mesa coja. Historia de la proclama de la Junta Tuitiva del 16 de julio de 1809. La Paz. PIEB.

Peralta, Víctor

2002 En defensa de la autoridad. Política y cultura bajo el gobierno del virrey Abascal. Perú, 1806-1816. Madrid. CSIC.

2010 La independencia y la cultura política peruana, 1808-1821. Lima. Instituto de Estudios Peruanos.

Pena González, Miguel

2011 "La excomunión de los insurgentes de La Paz. Validez canónica de las actuaciones del obispo La Santa y Ortega". Anuario de Estudios Bolivianos, Archivísticos y Bibliográficos. Sucre. no 16, pp. 498-586.

Ponce Sanginés, Carlos y García, Raúl Alfonso (recops.)

1953 Documentos para la historia de la revolución de 1809. La Paz. Biblioteca paceña - Alcaldía municipal. Volumen I.

1954 Documentos para la historia de la revolución de 1809. La Paz. Biblioteca paceña - Alcaldía municipal. Volumen II.

Ponce SAnginés, Carlos (recop.)

1954a Documentos para la Historia de la revolución de 1809. La Paz. Biblioteca paceña - Alcaldía municipal. Volumen III.

1954b Documentos del Archivo del conde de Guaqui. La Paz. Biblioteca paceña - Alcaldía municipal. Volumen IV, segunda parte.

RiVERA, Ana

1972 Murillo. Oficios y cartas. La Paz. Ed. Cooperativa Artes Gráficas.

Roca, José Luis

1998 1809. La revolución de la Audiencia de Charcas en Chuquisaca y La Paz. La Paz. Ed. Plural.

2007 Ni con Lima ni con Buenos Aires. La formación de un Estado nacional en Charcas. Lima. IFEA-Plural.

Rodríguez O., Jaime E.

1996 La independencia de la América española. México. Fondo de Cultura Económica.

Rodríguez O., Jaime E. (ed.)

2005 Revoluciones, Independencia y las nuevas naciones de América. Madrid. Fundación Mapfre-Tavera. 


\section{Ternavasio, Marcela}

2009 Historia de la Argentina, 1806-1852. Buenos Aires. Siglo XXI Editores. 2010 "De la crisis del poder virreinal a la crisis del poder monárquico: Buenos Aires, 1806-1810". En BREÑA (ed.), pp. 265-298.

\section{VÁzQUez Machidado, Humberto}

1991 La Revolución de La Paz de 1809. Para una biografía de Pedro Domingo Murillo. La Paz. Juventud. 